\title{
Design and Implementation of IOT based Smart Security and Monitoring for Connected Smart Farming
}

\author{
Laxmi S. Shabadi \\ Assistant Professor, Dept. of CSE \\ B.L.D.E.A'S Dr. P.G.Halakatti College of \\ Engineering and Technology, Vijayapur, \\ Karnataka, India
}

\author{
Hemavati B. Biradar \\ Student, Dept of CSE \\ B.L.D.E.A's Dr. P.G.Halakatti College of \\ Engineering and Technology, Vijayapur, \\ Karnataka, India
}

\begin{abstract}
India is a country which is having more population and it is very important to feed the food sufficiently to all the people. The main thing which is needed to fulfil this requirement is well equipped "agriculture" with enough water and minerals in the soil maintaining this is bit problematic. So integrating the agriculture field with Technology will make sound. Automatic soil features and condition fetching and decision taking can be done by using sensors and actuators, growing the seed and getting the yield is not the only thing, we can also provide security to farm land as well as to the product(obtained yield).
\end{abstract}

\section{Keywords}

Internet of Things, Security System, Smart Farming.

\section{INTRODUCTION}

Agriculture is the main occupation of India like countries and farmers are the backbone of our country. It is the duty of every person to think about agriculture and farmer and provide solution to the problems which are currently arising in the field of agriculture [2].

Now it is the time to think about "Internet of Things" which can provide more flexible and easy to use and provide more functionality in the agriculture. "Internet of Things" (IOT) will provide all work done and information updates and current status of the field to the person from anywhere and anytime [7]. Nowadays farmers also updated, improved. They also giving importance to the education and thinking about technology. Smart phones have been already in use in all villages. So it is easy to reach the farmers from internet. As we know there is insufficient water supply to the crops. Different crops needs different amount of water [4]. So providing the water as per the need without wasting water is important. Basically there is a huge amount of population it is good that all people should be served. It is necessary to grow more yields, which will feed all population without wasting the natural resources, proper usages in the agriculture field is the intelligence. This can be done by using the sensors, which will sense and give the information about requirement [1]

Nowadays security is the major thing which is going to be considered in every field. Same like, providing security in the agriculture is the best thing to consider [9]. Anything to the field which get entry can be fetched by implementing the security. The enhanced work to do is, providing the intelligence to all security system, so that it can control other electronic devices.

Information can be gathered from all sensors which are located on different farm lands [5], so that information can be gathered, stored and analysed which can guide for taking decision in other words act like a expert [6].
The smart agriculture with intelligent security system will be the convenient way to get the security to the field as well as to the grain store. In this paper we gave an introduction about security device implementation, which will get the information based upon the sensed data.

\section{RELATED WORK}

As we all know that nowadays we are giving keen interest in security because world is becoming very sensitive and there is much fear about threats, thieves, dangerous causes etc.

Till now security is given to the software systems [9] like layers of IOT systems. Many problems like unauthorised access, spoofing, malicious code infection, man-in-the-middle attack, DoS attack sniffing attack, etc. Providing security to different layer problems has been done.

Also security to cloud is given, in which the stored data can be fetched and accessed and misused. So this has been prevented and maintained.

To get protect from these kinds of problems we need to get alter every time about everything. Even in agriculture system people use more costly hardware and fertilizers etc. there should be the implementation of security system. Now it is the time to give security and protection to the agriculture fields.

\section{METHODOLOGY}

In the proposed work, we introduce our internet based smart farming system with security.

\section{A. Implementation}

The farming system is a rough system in which the things which are going to be used should be portable and the usage should be taken care. Now we are considering four parameters in which we are interested to get the data from field and addition to this, integrating security system with the existing system.

The information can be got from the field through different types of sensors and raspberry pi act as a server which will make decision and activate controllers.

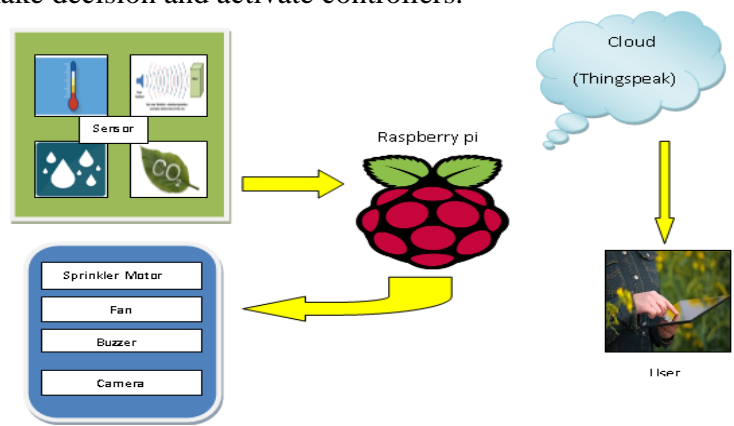

Figure 1: System block Diagram 
Different sensors will sense the current updates about the field and send it to raspberry pi which will analyze the data and make decision, which actuators can be activated based upon their respective sensor values. Example, if temperature in the soil is more than the threshold values then the motor of sprinkler will be activated to supply water to the field. Similarly for Gas -buzzer, for Humidity-Fan, for Motioncamera. Then the values taken by the raspberry pi will be sent to the Things Speak in which the data will be represented in graphical representation, so that user can access it and can get information about variations happened in the field.

The each part of this whole set up is in different layers based upon their functionality. For this implementation we made ready some set of to experiment. We used four sensors, their respective four controllers and raspberry pi which is shown in figure 1 .

The hardware and software coordination will lead to most wonderful product and that product can be used in any application field and new ideas may get arise. As we know technology has begun to run like anything. The connection of hardware components should be done very carefully. If any mistake happens then it may lead to get damage of hardware components. Working with electricity is not the easy thing. We need to connect the components when we have complete knowledge about it.

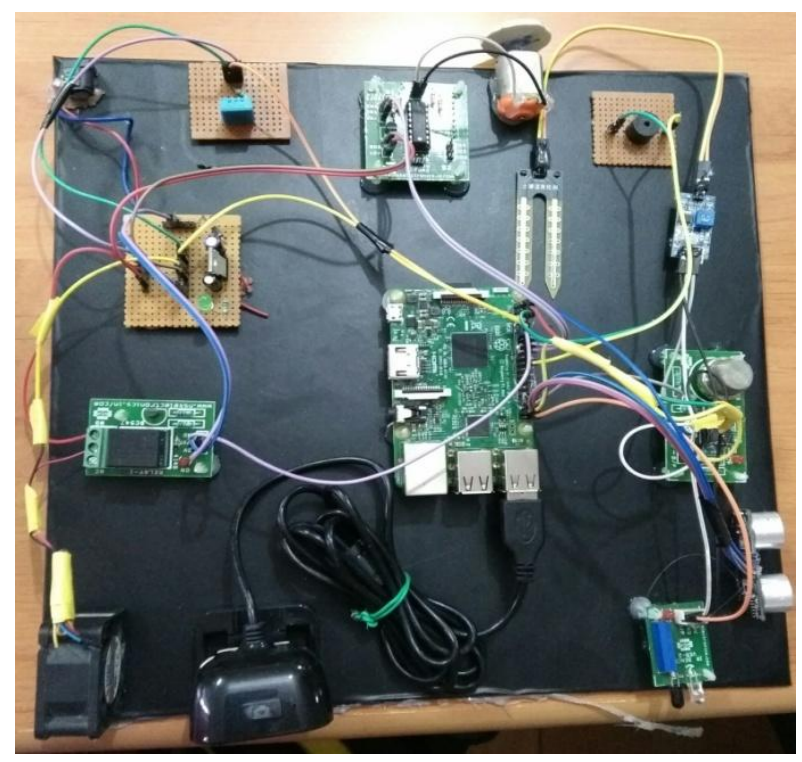

Figure 2: System Set up

The sensors and controllers (actuators) should be connected to some points in the Raspberry Pi . Raspberry Pi consists of 40 pins, in that some are GPIO pins, some are GND, some are IDEEPROM pins and some are few voltage pins. Input and Output devices can be connected to the General Purpose Input Output (GPIO) pins. The connection as well as hardware kit is shown in figure 2 .

Before this, basically in the Linux Operating System based raspberry Pi should have software part in it. To provide this we need to install software Python code in SD card. All functionality which is necessary for us should be written. And SD card should be inserted in the socket which is present on the Raspberry Pi hardware device.

Then for giving input as text or for selecting some option keyboard and mouse are connected to USB ports. There are four USB ports for this Raspberry Pi. We used two for keyboard and mouse. And one USB port for connecting camera.

Another one socket (HDMI) is provided for connecting monitor. One more socket (ETHERNET) for connecting LAN cable for giving internet connection.

Apart from this we used a relay device for triggering the fan. Power sharing circuit board which will provide power to relay, DHT, motor driver, fan, which intern provided power through adapter. Motor driver is used which will help to run motor.

\section{B. System Components}

The hardware devices which are used in this implementation are listed in below table 1 with their functionality for what purpose they have been used to do work.

\begin{tabular}{|c|c|c|}
\hline SI.NO. & Hardware & Functionality \\
\hline 1. & Raspberry Pi & $\begin{array}{l}\text { It will act like an operating } \\
\text { system and CPU which } \\
\text { helps for decision making. }\end{array}$ \\
\hline 2. & $\begin{array}{c}\text { Temperature } \\
\text { Sensor }\end{array}$ & $\begin{array}{l}\text { This will sense the water } \\
\text { content in the soil and send } \\
\text { it to raspberry pi. }\end{array}$ \\
\hline 3. & Gas Sensor & $\begin{array}{l}\text { This will sense any gas } \\
\text { which is present in the field } \\
\text { area. }\end{array}$ \\
\hline 4. & PIR Sensor & $\begin{array}{l}\text { It will sense the motion } \\
\text { based upon the heat of } \\
\text { moving object. }\end{array}$ \\
\hline 5. & URD Sensor & $\begin{array}{l}\text { It will sense and measure } \\
\text { the distance of the object } \\
\text { which is moving. }\end{array}$ \\
\hline 6. & DHT Sensor & $\begin{array}{l}\text { This will sense the humidity } \\
\text { of the environment. }\end{array}$ \\
\hline 7. & FAN & $\begin{array}{l}\text { This actuator will get } \\
\text { activate when the humidity } \\
\text { value crosses the threshold } \\
\text { value. }\end{array}$ \\
\hline 8. & Buzzer & $\begin{array}{l}\text { This device will make sound } \\
\text { when the gas is detected in } \\
\text { the field area. }\end{array}$ \\
\hline 9. & Motor & $\begin{array}{l}\text { This is the device which will } \\
\text { be further connected to } \\
\text { sprinkler. This will get start } \\
\text { when there no water content } \\
\text { in the soil. }\end{array}$ \\
\hline 10. & Camera & $\begin{array}{l}\text { This will get the snapshot of } \\
\text { a field when the motion of } \\
\text { any object is detected. }\end{array}$ \\
\hline
\end{tabular}




\section{RESULT \& DISCUSSION}

Now this is the time to discuss about the major part of this whole implementation.

\section{A. Cost and Analysis}

Getting the solutions is not at all a big deal there may be different solutions for single problem. It is the intelligence to choose the best efficient and low cost solution to a problem.

In the agriculture it is compulsory to use hardware. But we have to check low cost which will do more work and finally which is more durable one.

The hardware which we have used for implementation is listed in below table 2 with their cost.

Table 2: Hardware Cost Estimation

\begin{tabular}{|c|c|c|}
\hline \\
\hline SI. NO. & HARDWARE & COST in rs \\
\hline 1. & Raspberry Pi & 2800 \\
\hline 2. & Camera & 800 \\
\hline 3. & Ultrasonic sensor & 249 \\
\hline 4. & IR sensor & 110 \\
\hline 5. & Moisture Sensor & 145 \\
\hline 6. & Humidity sensor & 120 \\
\hline 7. & Sprinkler Motor & 600 \\
\hline 8. & FAN & 150 \\
\hline 9. & Buzzer & 200 \\
\hline 10. & $\begin{array}{l}\text { Other devices } \\
\text { (approx) }\end{array}$ & 900 \\
\hline & Total & 6074 \\
\hline
\end{tabular}

B. Data Analysis in Cloud

Our main intention is to provide security to the agriculture field it can be a field or store room by putting intelligent camera system in the field as well as in store room. Basically we used four sensors they are: temperature, humidity, gas, motion detection sensors and as discussed above there are controllers too. Each sensor will do its work that is sensing the changes occurring in the environment, and these values will be stored and based upon them we can control the farm land. Automatically actuators are made to on/off by reading those sensor values.

For our experiment purpose we set the temperature sensor threshold value to 31 , if the value is more than this threshold value motor will start running. Then for humidity we took $0 / 1$ value, if ' 1 ' is detected fan will get run else it will stop itself. ' 1 ' indicates that humidity is present and ' 0 ' indicates humidity is not present. Same as humidity we took condition for gas sensor. If the value is ' 1 ' buzzer will beep which means some gas is present in the field else it will not make any sound. Even motion detection will also run on 0/1 conditions. It will print as motion detected and URD sensor will measure the distance of the object and camera is made to capture the image. Continuously for every second we made to read the values and check the values.

Then we have created one GUI for watching the current values from anywhere and anytime. For this functionality we opened one user account in Things Speak. Thing Speak will provide privacy to store the data in graphical representation way, which will make easy to look after the updates.

Thing Speak is an open source internet of things application and API to store and retrieve data from things using the HTTP protocol over the internet or via a local area network. Things Speak enables the creation of sensor logging applications, location tracking application and a social network of things with status updates.

Things Speak has integrated support from the numerical computing software MATLAB from math works. Allowing Things Speak users to analuze and visualize uploaded data using Matlab without requiring the purchase of a Matlab license from Math Works.

Why To Use Thing Speak to Collect Data?

Thing Speak is having two types of channel: private and public. The sensors are enabled to send data to cloud which in turn is made to store either in private or a public channel. By default Thing Speak will store data in private channel. We can make it to store it in public channel if we want to store data with others. We can analyze and visualize data, calculate new data, can interact with social media, web services and other devices when the data is stored in Thing Speak. The experimental value readings which are stored in cloud are shown in separate individual field charts which are shown in below figures 3-7.

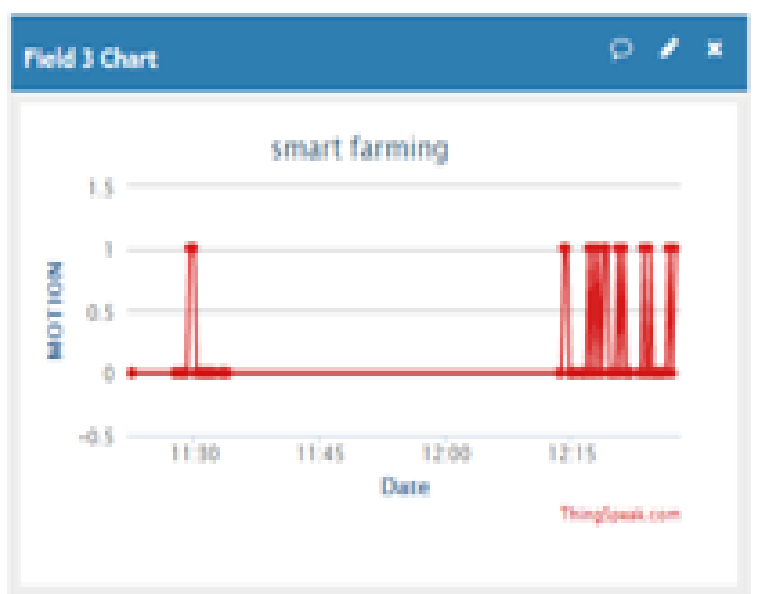

Figure 3: ThingSpeak's Motion Detected Readings 


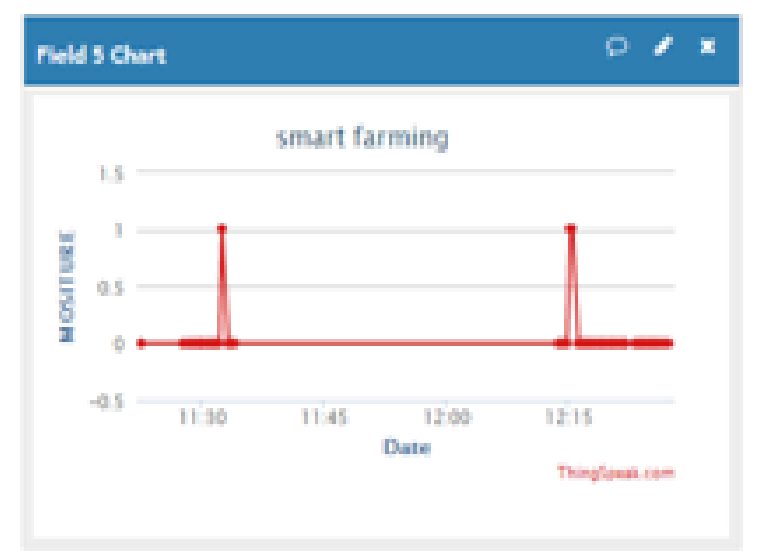

Figure 4:ThingSpeak's Moisture Detected Reading

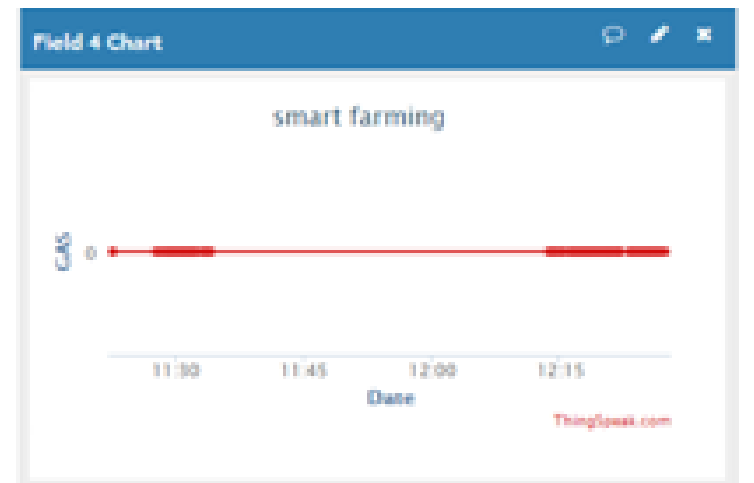

Figure 5: ThingSpeak's Gas Detected Readings

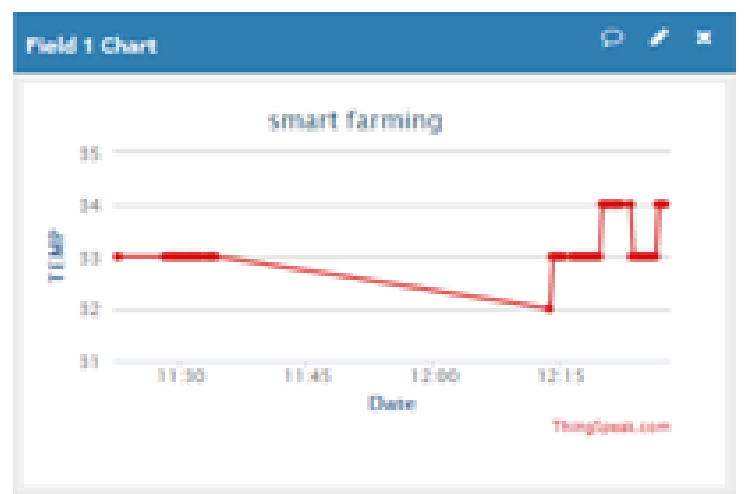

Figure 6: ThingSpeak's Temperature Readings

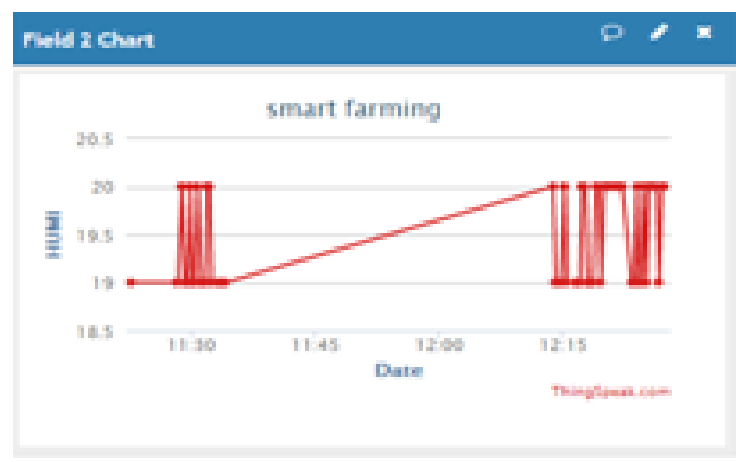

Figure 7: ThingSpeak's Humidity Readings

\section{CONCLUSION \& FUTURE WORK}

In the Agriculture, day to keep posted is most indispensable thing to concentrate. Particularly Security is the most essential thing which is mainly concentrated in this work. Getting the accurate values about update from the cloud which will lead to take decision. Automatic controlling of the farm field can be done without visiting. Future work is to applying the machine learning technique with large set of database will make to move auxiliary enhanced, precise, decision making. This will act like an expert.

\section{REFERENCES}

[1] Ahmad Harun, Mohamed Kassim, Ibrahim Mat, Siti Ramli, "Precision Irrigation using Wireless Sensor Network", IEEE,2015.

[2] M. K. Gayatri, J. Jayasakthi, Dr. G. S. Anandha Mala, "Providing Smart Agriculture Solutions to Farmers for better yielding using IOT",IEEE International Conference on Technological Innovations in ICT for Agriculture and Rural Development, 2015.

[3] Chandan Sahu, Pramitee Bahera, "A Low Cost Smart Irrigation control System ”, IEEE Sponsered $2^{\text {nd }}$ International Conference on Electronics and Communication System, 2015.

[4] Sonali Lagu, Prof. Sanjay Deshmukh, "Raspberry Pi for Automation of water treatment Plant", International Conference on Computing Communication Control and Automation, 2015.

[5] Minwoo Ryu, Jaeseok Yun, and three more, "Design and Implementation of a Connected Farm for Smart Farming System”, IEEE, 2015.

[6] Jorg Swetina, Guang Lu, and three more,"Toward A Standardized Common M2M Services Layer Platform:Introduction To OneM2M", IEEE, 2014.

[7] J.Gubbi, R.Buyya, S. Marusic, Marimuthu Palaniswami,"Internet of Things: A Vision, Architectural Elements, and Future Directions", 2014.

[8] P. Jayaraman, D. Palmer, etc, "Do-it-Yourself Digital Agricuture Applications with semantically Enhanced IOT Platform”, IEEE,2015.

[9] M. U. Farooq, Muhammad Waseem, etc,"A Critical Analusis in the Security Concerns of Internet of Things(IOT)", International Journal of Computer Applications,

2015 